\title{
Looking into van Gogh's paintings with Focused Ion Beam (FIB)
}

\author{
Ulrike Zeile*, Ralph Haswell** \\ * Carl-Zeiss NTS GmbH, D-73446 Oberkochen, Germany \\ ** Shell Global Solutions International B.V., 1031 CM Amsterdam
}

Vincent van Gogh $(1853$ - 1890) is one of the most famous artists of the Impressionist Period. He left the studio to create colors rich in nuances and as close as possible to the original.

Recently, some of his paintings have been undergoing extensive examination in Amsterdam [1]. The aim is to prepare reconstructs of his pictures, using original materials to the greatest extent possible (Fig. 1). The object is to gain knowledge of how artists created their paintings and get a deeper knowledge of their techniques. This can be used to develop improved conservation techniques and through the detailed characterization of the specific pigments we hope to generate a typical "fingerprint" of the artist.

Oil painting belongs to a category of very brittle and porous sample types. The pigments are held together with organic binder agents, filler and further less well known additives. This composition makes classical TEM sample preparation impossible. On the other hand, pure SEM analysis of a block face was inappropriate for an exact composition analysis, because of the poor spatial resolution and the lack of phase information.

The Zeiss CrossBeam ${ }^{\circledR}$ Technology [2] is used to determine the area of interest, localize characteristic particles by EDX and prepare directly at this particle a TEM lamella (Fig. 2) in order to analyze the materials with the highest possible resolution. For this work we have used a Zeiss 1540 EsB CrossBeam ${ }^{\circledR}$ with both, in-situ and ex-situ lift out technique of the lamellas (Fig. 3) for the following analysis by Transmission Electron Microscopy (TEM).

Barium Sulfate, one main component in the ground of van Gogh's paintings has become of great interest with regard to authentication. He and Paul Gaugin (1848 - 1903), during the time, they were working together (1888), may have used a certain type of Barite with a typical Strontium content.

[1] This work was done in company with the Shell International Chemicals and Van Gogh Museum, Amsterdam

[2] P. Gnauck et. al., Microsc. Microanal., Vol. 9 (Suppl.3), 524 (2003) 


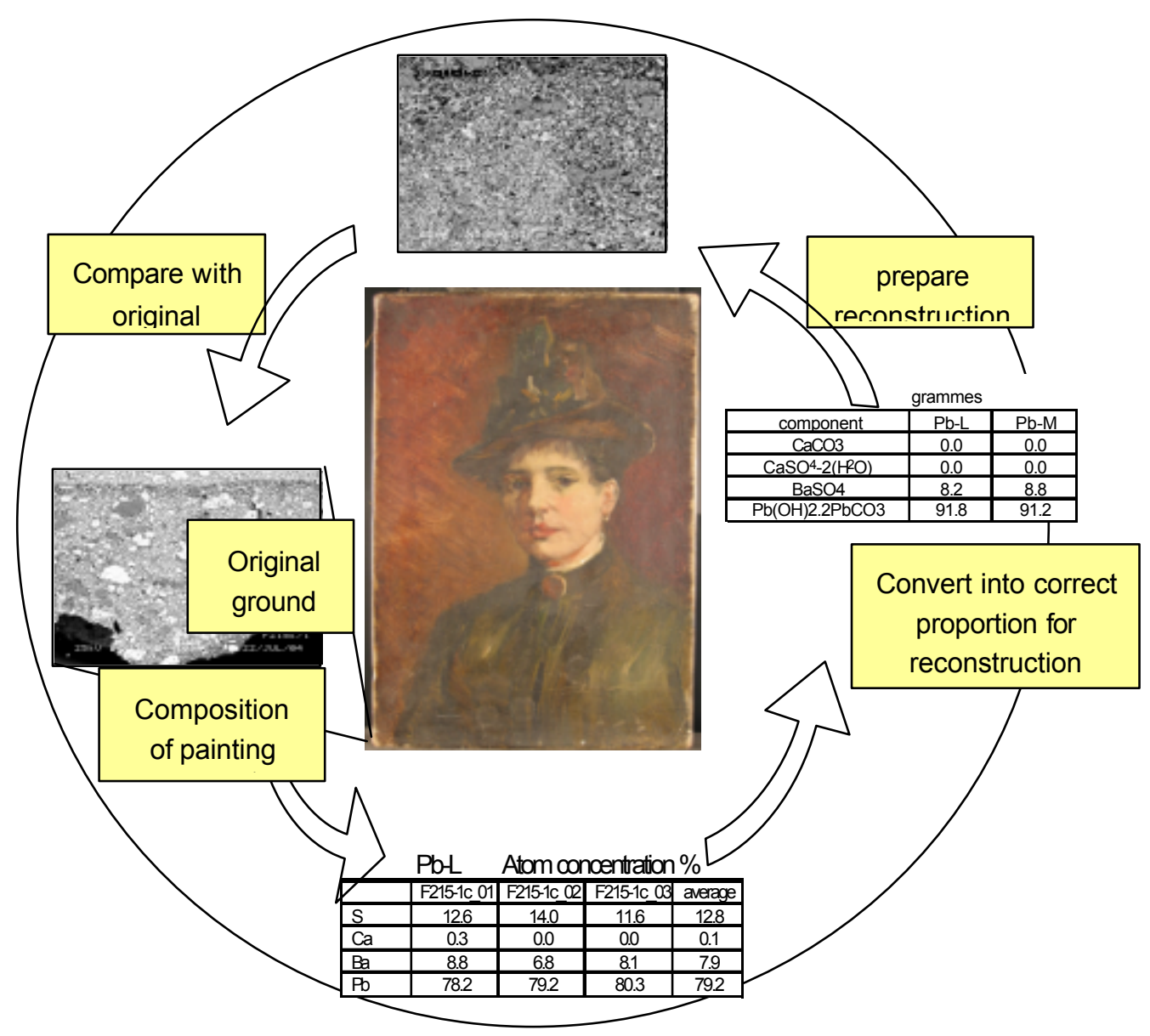

(Fig. 1) Reconstruction circle of van Gogh's Portrait of a woman
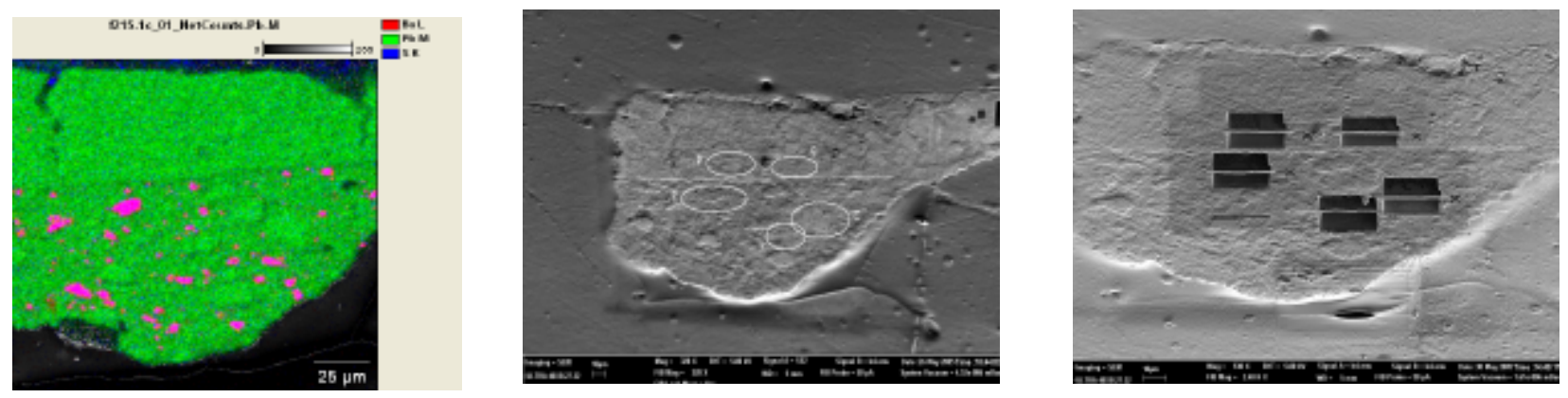

(Fig. 2 a - c) See ground paint (lower area) and colour paint (upper area) are localized in the sample. Pigment particles of interest are localized by EDS leads to side specific TEM lamella production.

(Fig. $3 \mathrm{a}, \mathrm{b}$ ) Example of a TEM lamella in the painting ground.
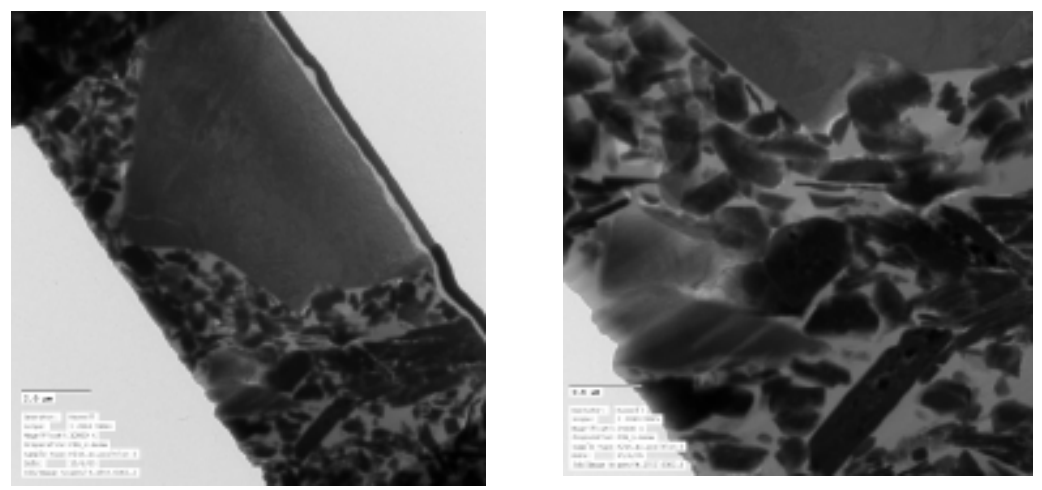